\title{
UK and Germany put the squeeze on CERN's plans for new accelerator
}

Munich. Last-minute attempts by the British and German governments to impose stringent financial conditions on the construction of Europe's planned Large Hadron Collider (LHC) may bring an element of brinkmanship to next Friday's (24 June) meeting of the council of the European Laboratory for Particle Physics (CERN) in Geneva.

With all 19 member states in favour - at least in principle - of proceeding with the LHC it is unlikely that the council will block approval for the project. The demise of the US Superconducting Super Collider (SSC) means that the LHC would be the world's largest particle accelerator and its best prospect for detecting predicted fundamental particles such as the Higg's boson.

But such approval will not be as automatic as some had hoped, because the CERN management has so far dismissed as unacceptable a German/British proposal to change a vital voting rule for agreeing on the inflation-linked rises in annual subscriptions from member states.

At present such rises, needed to cover the additional costs of personnel and materials, have to be agreed by a simple majority, although under an amendment introduced two years ago the countries in favour of an increase must contribute more than 55 per cent of the total budget. This rule is intended to ensure that the growing number of smaller member states cannot block the wishes of CERN's main contributors, namely Germany (which provides 22.5 per cent of the budget), France (17.5 per cent), Italy (15.5 per cent), the United Kingdom (13.5 per cent) and Spain ( 7.5 per cent).

Citing financial pressures at home, both Britain and Germany now want an individual right of veto, and are pressing for a rule requiring any inflation-linked rise to be agreed unanimously. But such a move is unlikely to be welcomed by many other member states, particularly because it would also give a veto to small member countries.

Furthermore, given the expected difficulty in reaching unanimous agreement, the move could effectively hold the budget level in cash terms at 1995 prices for the whole of the LHC construction programme, and the first two years of experiments (1995-2005). This could reduce the purchasing power of

\section{as Spain gets cut-rate membership}

Munich. A long-standing dispute between Spain and CERN over Spain's membership subscription is likely to be resolved next week with an agreement to give the country a discount averaging 23 per cent over the next five years.

Spain has withheld payments for over two years. It argues that, because of a weak domestic base in particle physics, it has too few staff and visiting scientists in Geneva, and wins less than one per cent of the industrial contracts issued each year, despite contributing 7.5 per cent of the laboratory's budget.

Sympathetic to Spain's severe economic problems, CERN had offered a 20 per cent discount in its subscription over the next five years - provided that it paid its existing debts. Spain is now offering a compromise believed to be acceptable to CERN, under which it will pay its debt by underwriting a bank loan to CERN.

In exchange, Spain will be allowed a decreasing reduction on its subscription over the next five years, starting at 40 per cent in 1994 and ending with 10 per cent in 1998. Spain is to consider setting up a research institute for particle physics.

Six other countries also have a special agreement for reduced subscriptions, loosely based on gross domestic product.
The four new members from central Europe - Poland, Hungary and the Czech and Slovak republics - pay only token contributions. Negotiations are taking place to bring them up to full contribution by the year 2000 . But even then they are likely to contribute only a few per cent of the total budget of the LHC.

Greece negotiated a 60 per cent reduction in its subscription in the 1970 s by arguing that its scientific community was so weak that it reaped little benefit from its membership. But now both sides agree that Greece's particle physics community has prospered, thanks to training at CERN, and Greece has agreed to increase its contribution, aiming to reach its full level by 2001.

But the most important case is Germany, whose contribution should have risen after reunification. But because the costs of reunification were themselves so high, CERN agreed that Germany's contribution should remain unchanged (at 22.5 per cent of the budget) until 1995, with a possible extension of a further two years. The extension is likely to be a very sensitive issue when it comes up for discussion this year with countries such as France likely to object strongly to any further concessions.

Alison Abbott

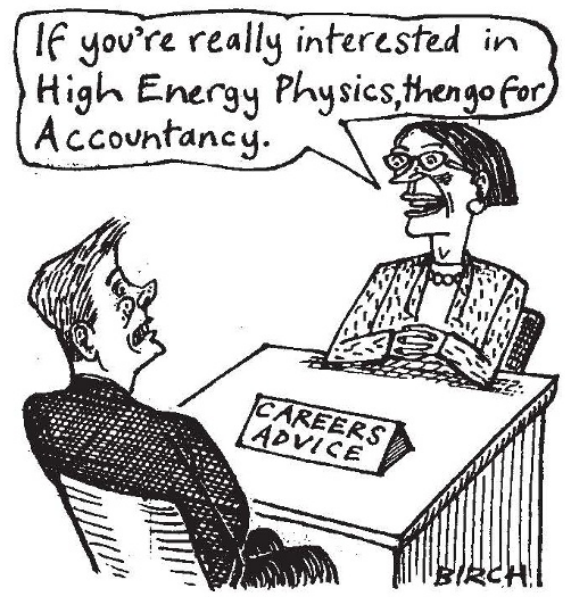

the budget by 30 per cent at a time when CERN already has a large shortfall in cash.

Under CERN's proposed construction programme, the LHC will cost an estimated 2.6 billion Swiss francs (US\$1.8 billion), SFr500 million more than the member states would pay out of their normal, inflationlinked contributions. Christopher Llewellyn Smith, the laboratory's director-general, proposes to make up this shortfall in one of two ways (see Nature 366, 714; 1993).

The preferred option would be to raise the money from non-member countries, particularly the United States, Japan and Canada, whose own particle physics programmes have been left in the lurch by the demise of the SSC. Positive signals have come from these countries, particularly from physicists in the United States (see Nature 369,266 ; 1994); but none want to start negotiations until the LHC has been formally approved.

Lacking such contributions, the second option would be to extend the construction phase by two years, delaying the start of experiments until the beginning of 2005 . But CERN is keen to avoid such a delay, as experiments on the current CERN accelerator (LEP) will come to an end in 1999.

Llewellyn Smith wants next week's council meeting to take a clear decision on initiating the construction programme so that he can put these uncertainties to rest. The decision does not have to be unanimous. But CERN is keen for a public show of harmony, as the non-member states it is courting will be present at the meeting as observers.

The final days before the meeting are therefore likely to see some hard bargaining between Llewellyn Smith and the British and German delegations. One compromise could be a temporary agreement to fix contributions in cash terms, in exchange for further trimming of CERN costs - 